Saudi Journal of Oral and Dental Research

Abbreviated Key Title: Saudi J Oral Dent Res

ISSN 2518-1300 (Print) |ISSN 2518-1297 (Online)

Scholars Middle East Publishers, Dubai, United Arab Emirates

Journal homepage: https://saudijournals.com

\title{
Dental Negligence Score among Dental Students
}

Asmi Shaheen ${ }^{1}$, Salsabeel Amjad ${ }^{2}$, Hafiza Attqua Fatima ${ }^{3}$, Tayyeba Zubair ${ }^{4}$, Amina Tariq ${ }^{5 *}$

${ }^{1}$ FCPS, Assistant Professor Orthodontics, de 'Montmorency College of Dentistry, Lahore, Pakistan
${ }^{2}$ BDS, de 'Montmorency College of Dentistry, Lahore, Pakistan
${ }^{3}$ BDS 3rd year, de 'Montmorency College of dentistry, Lahore, Pakistan
${ }^{4}$ PGR, Orthodontics, de 'Montmorency College of Dentistry, Lahore, Pakistan
${ }^{5}$ Postgraduate Research Coordinator, University College of Medicine and Dentistry, University of the Lahore, Pakistan

DOI: $\underline{10.36348 / \text { sjodr.2021.v06i01.011 }}$

| Received: 29.12.2020 | Accepted: 12.01.2021 | Published: 16.01.2021

*Corresponding author: Amina Tariq

Abstract

Dental neglect can be defined as attitude and behavior towards oral health which can have detrimental effects on individual's oral health, e.g. negligence in maintaining at home dental care and dental visits for professional dental care. Oral health is a part of general health care system and negligence in oral hygiene can affect the quality of life too. The aim of the study was to assess dental negligence and oral hygiene status among undergraduates' students. Study consisted of 20 questionnaire including names and year of study using dental neglect scale and were circulated among undergraduates' students. Total 156 students responded to the questionnaire. Out of 156 student's perception of $83.3 \%$ students has changed towards oral hygiene practices after entering into BDS program. Dental neglect is easier to use in practice and it shows that degree of dental neglect is found among dental undergraduate students and variation also exists among students of all four years.

Key words: Oral hygiene, undergraduate students, oral hygiene negligence, dental care, oral health practices, dental neglect scale.

Copyright (C) 2021 The Author(s): This is an open-access article distributed under the terms of the Creative Commons Attribution 4.0 International License (CC BY-NC 4.0) which permits unrestricted use, distribution, and reproduction in any medium for non-commercial use provided the original author and source are credited.

\section{INTRODUCTION}

Maintenance of meticulous oral health practices is imperative for maintaining healthy and disease-free oral cavity. Failure to maintain oral hygiene can lead to dental decay and deterioration pf periodontal health which can ultimately lead to tooth decay.

Dentists have and important role in motivating, educating and improving general public oral health. Therefore, it is important for future dentists to acquire authentic knowledge and positive attitude related to dental health in order to inculcate positive attitude towards dental health in the society and helping the society for the prevention of oral diseases $[1,2]$.

The term "DENTAL NEGLECT" can be defined as the behavior and attitudes which are likely have detrimental consequences on individual's oral health [3].

Dental Neglect is the failure to fulfill the known knowledge of oral health care for proper maintenance of oral cavity [4].
Dental health can't be separated from general health since oral diseases may be a manifestation of some widespread systemic diseases [5]. Its accepted within health care community that oral infections and other systemic diseases are interlinked. Oral health is elementary to general health and wellbeing. In addition to poor oral health, dental neglect is associated to physical and social disabilities.

Prevention is always better than cure. People need to be very conscientious and attentive to maintain oral hygiene for prevention of oral diseases. Preventive care is effective, efficient and much durable habit to maintain better oral health, but few people take regular home dental care and a handful of people visit dentists for professional dental care to keep their oral cavity healthy.

Dental neglect scale (DNS) is an important measure for measuring dental neglects. The dental neglect scale assesses the extent to which individual cares for his/her teeth, receives professional care, and consider importance of oral health.

Thus, a survey was commenced to assess dental negligence and oral health status among

Citation: Asmi Shaheen et al (2021). Dental Negligence Score among Dental Students. Saudi J Oral Dent Res, 6(1): 54-58. 
undergraduates' students using dental neglect questionnaire.

\section{MATERIALS AND METHODS}

A Questionnaire based survey using dental neglect scale was used to assess dental negligence among dental under graduates' students. Selfadministered closed ended questions were circulated among students using online google forms.

The study was conducted among 150 dental undergraduate students mainly of public dental college of Punjab Pakistan. The study had 20 questions including their names and year of study using dental neglect questionnaire [Table No.3] in a way to ensure the comprehensibility of students. The survey helped in assessing the knowledge and oral hygiene practices according to WHO recommendations among undergraduates' students and to know the reasons of dental neglect among them.

\section{RESULTS}

Total 152 students responded to the survey. According to the survey $95.4 \%$ students brush on daily basis. Other oral hygiene practices among students are as follow:

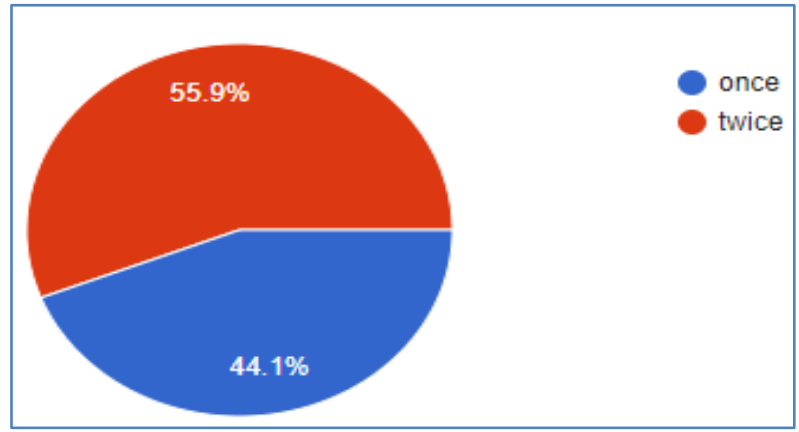

Frequency of brushing

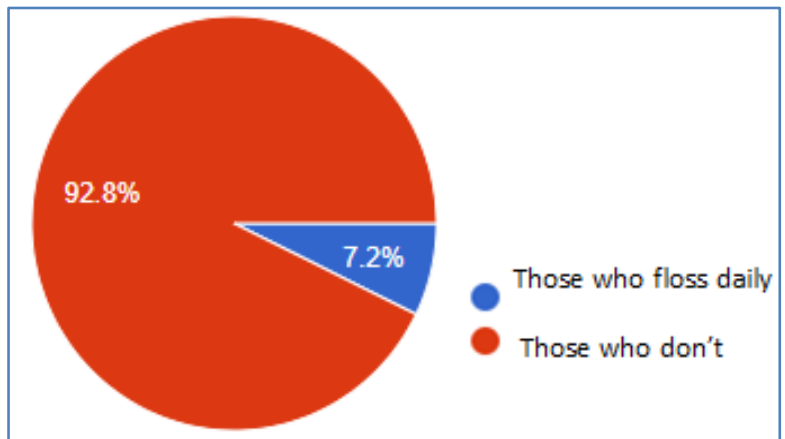

Students who floss daily

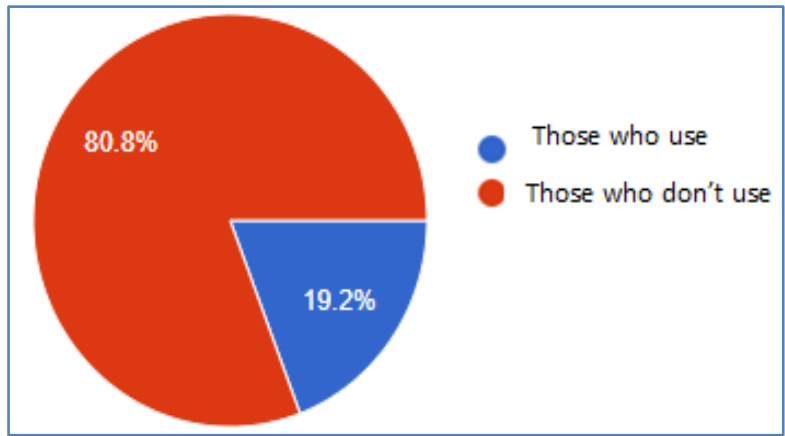

Students using mouthwash regularly

All four years of students participated in the survey and the results show the variation in degree of neglect among different years of students. Students do brush daily but half of them brush once in a day. $92.9 \%$ of students don't floss and $80.9 \%$ don't use mouthwash despite of being there in dental education program. Data regarding the response of participant about brushing technique [Table No.1] revealed only $62.8 \%$ students brush their teeth according to steps advised by WHO and $77.6 \%$ students brush their teeth properly using proper method. $75 \%$ students use Bass technique while Stillman's used by only $25 \%$ students.

Table-1: Response of students about brushing techniques

\begin{tabular}{|l|l|l|}
\hline & YES & NO \\
\hline Do you brush your teeth according to steps advised by WHO & $62.8 \%$ & $37.2 \%$ \\
\hline Do you brush your teeth using proper method & $77.6 \%$ & $22.4 \%$ \\
\hline Which technique do you use? & BASS TECHNIQUE 75\% & $\begin{array}{l}\text { STILLMAN } \\
\text { TECHNIQUE 25\% }\end{array}$ \\
\hline
\end{tabular}

The data in [Table no.2] reveal that $61.5 \%$ students have undergone dental treatment in past which indicate their neglect towards oral hygiene and only $21.2 \%$ students have a family dentist. Only $16 \%$ go for regular dental checkups which shows their lack of interest in oral hygiene maintenance although $82.7 \%$ students think that scaling is important for oral hygiene maintenance but only $19.2 \%$ go for scaling after six months as recommended. Many of the students claim that their perception has been changed a lot after entering in BDS program, which is very helpful for them in practicing oral hygiene measures according to recommendation. 
Table-2: Students' attitude towards professional dental care

\begin{tabular}{|l|l|l|}
\hline & YES & NO \\
\hline Have you undergone any dental procedure in past & $61.5 \%$ & $38.5 \%$ \\
\hline Do you have a family dentist? & $21.2 \%$ & $78.8 \%$ \\
\hline Do you go for regular dental checkups? & $16 \%$ & $84 \%$ \\
\hline Do you think scaling is important for maintaining oral hygiene? & $82.7 \%$ & $17.3 \%$ \\
\hline Do you go for scaling every six months as recommended & $19.2 \%$ & $80.8 \%$ \\
\hline
\end{tabular}

Response distribution to dental neglect score is added in [Table No.3] which shows the degree of dental negligence among undergraduate students.

Table-3: Response distribution to dental neglect score (DNS) items $(n=156)$

\begin{tabular}{|l|l|l|l|l|l|}
\hline & $\begin{array}{l}\text { Strongly } \\
\text { disagree }\end{array}$ & Disagree & Neutral & Agree & $\begin{array}{l}\text { Strongly } \\
\text { agree }\end{array}$ \\
\hline $\begin{array}{l}\text { I consider my Dental health as important as } \\
\text { physical health. }\end{array}$ & $1(0.6 \%)$ & $3(1.9 \%)$ & $15(9.6 \%)$ & $28(17.9 \%)$ & $109(69.9 \%)$ \\
\hline Flossing helps in taking good care of my teeth. & $0 \%$ & $5(3.2 \%)$ & $34(21.8 \%)$ & $46(29.5 \%)$ & $71(45.5 \%)$ \\
\hline $\begin{array}{l}\text { Mouth wash are helpful in maintaining oral } \\
\text { hygiene. }\end{array}$ & $2(1.3 \%)$ & $10(6.4 \%)$ & $45(28.8 \%)$ & $39(25 \%)$ & $60(38.5 \%)$ \\
\hline $\begin{array}{l}\text { Literature knowledge helps to maintain my oral } \\
\text { hygiene practically. }\end{array}$ & $4(2.6 \%)$ & $5(3.2 \%)$ & $36(23.1 \%)$ & $37(23.7 \%)$ & $74(47.7 \%)$ \\
\hline
\end{tabular}

\section{DISCUSSION}

It is of great importance that the future dental surgeons whose duty will be to motivate the patient and to give them all the basic instructions to able those to achieve a sufficient degree of oral hygiene should themselves be particularly conscious of the pathological effects of poor oral hygiene [6]. Also, literature, media and dentists are the basic sources of oral health education $[7,8]$.

It is evident from results of this research that oral hygiene negligence is common in Undergraduate students of even BDS program. Numerous studies in the past have shown that as the academic year progresses so does the oral health [9]. This shows that knowledge do help in maintaining oral health. Through their undergraduate studies it is logical for the students in the field of to develop and modify their attitudes towards oral health [10].

Dental neglect can be defined as a persistent failure in taking precautionary measures and taking necessary dental treatment to maintain oral health and to ensure freedom for pain and infection $[11,12]$. Most of the students do brush their teeth but don't use floss and mouthwash on regular basis [13-15] despite of being aware of the fact that both are important precautionary practices and so helpful in maintaining their oral hygiene. Students do brush their teeth twice or more frequently and the results were in accordance with previous results of Turkey and Jordan [16-18].

Mostly students do brush their teeth according to steps advised by WHO and most of them use Bass technique but still there are students who don't brush according to brushing techniques. Students of dental school have been taught multiple tines about the importance of regular dental check-up and still $84 \%$ of the students don't go for it.

Even students of dental education don't give enough importance to their oral hygiene as they give to their physical which is being evident by the number of students having their family dentists. More than half of the students don't have any family dentist to go to for their dental check-up.

Dental students are given a continuous exposure to oral health problems and their treatment possibilities and they are also taught the correct way to deal with them at early stages [19] to avoid any problem to get severe or to prevent any disease from occurring. But a lot of them don't practically implement the knowledge for their own benefit.

Scaling is a very basic procedure to keep our oral hygiene clean and to prevent any disease from occurring in our mouth by preventing the accumulation of plaque and bacteria. Most of the students know about its importance and its impact on maintaining oral hygiene still only $19.2 \%$ of the students go for scaling every six months as advised by WHO.

There are students present who being in dental education program still don't give equal importance to their oral hygiene as they are giving to their physical well-being. Some of them don't even consider that flossing and using mouthwash will help to maintain oral Hygiene in a better way. The behavior of oral health providers and their attitudes towards oral health could affect their capacity to deliver oral health and does might affect the oral health of patients [20-21]. 
Asmi Shaheen et al; Saudi J Oral Dent Res, Jan, 2021; 6(1): 54-58

Students agree that literature does help them to take good care of their oral hygiene practically but according to the responses they don't fully apply what they're being taught in dental schools. Although a profound knowledge and literature regarding physiological and pathological variations in accordance with the systemic conditions have been added in dental syllabus, its stress on practical implementation of oral hygiene practices remains uncertain [22].

DNS is an ideal tool for assessing attitude and behavior towards oral health. As well, it is a good scale for surveying that are aimed at identifying vulnerable groups to dental care [23-25].

\section{CONCLUSION}

Dental neglect is behavior which brings many unwanted consequences in oral health. Dental neglect is easier to use in practice and it shows that degree of dental neglect is found among dental undergraduate students and variation also exists among students of all four years.

The students should focus on practically implementing oral hygiene practices on themselves so that they can easily explain them to their patients and improve their oral hygiene status as well. Also, dental students should go for a regular dental checkup as it is easily accessible to them.

\section{ACKNOWLEDMENT}

I wish to express my sincere gratitude to Dr. Muhammad Ilyas (Associate professor, orthodontics) for providing me an opportunity to do my research on topic "Dental negligence score among dental graduates"

I sincerely thank for his guidance and encouragement in carrying out this research.

\section{REFERENCES}

1. Rahman, B., \& Al Kawas, S. (2013). The relationship between dental health behavior, oral hygiene and gingival status of dental students in the United Arab Emirates. European journal of dentistry, 7(1), 22.

2. Bertolami, C. N. (2001). Rationalizing the dental curriculum in light of current disease prevalence and patient demand for treatment: form vs. content. Journal of dental education, 65(8), 725735.

3. Pandey, V., Chandra, S., Kumar, H. D., Gupta, A., Bhandari, P. P., \& Rathod, P. (2016). Impact of dental neglect score on oral health among patients receiving fixed orthodontic treatment: A crosssectional study. Journal of International Society of Preventive \& Community Dentistry, 6(2), 120.

4. Dannan, A. (2010). An update on periodonticorthodontic interrelationships. Journal of Indian Society of Periodontology, 14(1), 66.
5. Kumar, S., Kriplani, D., Shah, V., Tadakamadla, J., Tibdewal, H., Duraiswamy, P., \& Kulkarni, S. (2010). Oral health attitudes and behaviour as predisposing factor for dental caries experience among health professional and other professional college students of India. Oral health \& preventive dentistry, 8(2).

6. Tenenbaum, H. (1980). Impact of a periodontal course on oral hygiene and gingival health among senior dental students. Community Dentistry and Oral Epidemiology, 8(7), 335-338.

7. Lin, H. C., Wong, M. C. M., Wang, Z. J., \& Lo, E. C. M. (2001). Oral health knowledge, attitudes, and practices of Chinese adults. Journal of Dental Research, 80(5), 1466-1470.

8. Paik, D. L., Moon, H. S., Horowitz, A. M., Gift, H. C., Jeong, K. L., \& Suh, S. S. (1994). Knowledge of and practices related to caries prevention among Koreans. Journal of public health dentistry, 54(4), 205-210.

9. Polychronopolou, A., Kawamura, M., Arthanasouli, T. (2002). Oral self-care behavior in dental school students in Greece, J Ora Sci, 44; $73-$ 77.

10. Kawamura, M., Spadafora, A., Kim, K. J., \& Komabayashi, T. (2002). Comparison of United States and Korean dental hygiene students using the Hiroshima university- dental behavioural inventory (HU- DBI). International dental journal, 52(3), 156-162.

11. Simons, D., Pearson, N., \& Evans, P. (2013). A pilot of a school-based dental treatment programme for vulnerable children with possible dental neglect: the Back2School programme. British dental journal, 215(8), E15-E15.

12. Acharya, S., Pentapati, K. C., \& Bhat, P. V. (2013). Dental neglect and adverse birth outcomes: a validation and observational study. International journal of dental hygiene, 11(2), 91-98.

13. Al-Omari, Q. D., \& Hamasha, A. A. (2005). Gender-specific oral health attitudes and behavior among dental students in Jordan. J Contemp Dent Pract, 6(1), 107-14.

14. Östberg, A. L., Halling, A., \& Lindblad, U. (1999). Gender differences in knowledge, attitude, behavior and perceived oral health among adolescents. Acta odontologica scandinavica, 57(4), 231-236.

15. Tada, A., \& Hanada, N. (2004). Sexual differences in oral health behaviour and factors associated with oral health behaviour in Japanese young adults. Public health, 118(2), 104-109.

16. Peker, I., \& Alkurt, M. T. (2009). Oral health attitudes and behavior among a group of Turkish dental students. European journal of dentistry, 3(1), 24.

17. Polychronopoulou, A., \& Kawamura, M. (2005). Oral self- care behaviours: comparing Greek and Japanese dental students. European Journal of Dental Education, 9(4), 164-170. 
18. Yildiz, S., \& Dogan, B. (2011). Self-reported dental health attitudes and behaviour of dental students in Turkey. European journal of dentistry, 5(3), 253.

19. Chattopadhyay, A. (1990). Self-assessed oral health awareness and unmet demands among medical and dental professionals in Calcutta. Community dentistry and oral epidemiology, 18(3), 163-164.

20. Hamasaki, T., Kato, H., Kumagai, T., \& Hagihara, A. (2017). Association between dentist-dental hygienist communication and dental treatment outcomes. Health Communication, 32(3), 288-297.

21. Brown, L. F. (1996). A comparison of patients attending general dental practices employing or not employing dental hygienists. Australian dental journal, 41(1), 47-52.

22. Kumar, S., Motwani, K., Dak, N., Balasubramanyam, G., Duraiswamy, P., \&
Kulkarni, S. (2010). Dental health behaviour in relation to caries status among medical and dental undergraduate students of Udaipur district, India. International journal of dental hygiene, 8(2), 86-94.

23. Jamieson, L., \& Thomson, M. U. R. R. A. Y. (2002). Dental health, dental neglect, and use of services in an adult Dunedin population sample. New Zealand Dental Journal, 98, 4-8.

24. Thomson, WM, Locker, D., \& Poulton, R. (2000). Incidence of dental anxiety in young adults in relation to dental treatment experience. Community Dentistry and Oral Epidemiology , 28 (4), 289-294.

25. Coolidge, T., Heima, M., Johnson, E. K., \& Weinstein, P. (2009). The dental neglect scale in adolescents. BMC Oral Health, 9(1), 2. 